\title{
LINGUAGEM AUDIOVISUAL E USO DIDÁTICO DE RECURSOS DIGITAIS NA FORMAÇÃO DE PROFESSORES E CIÊNCIAS
}

\author{
AUDIOVISUAL LANGUAGE AND DIDATIC USE OF DIGITAL RESOURCES IN TEACHER \\ EDUCATION
}

\begin{abstract}
https://orcid.org/0000-0002-6185-411X Pedro de Almeida Cunha ${ }^{\mathrm{A}}$ https://orcid.org/0000-0001-7550-2775 Bianca Maria Rêgo Martins ${ }^{B}$ (D) https://orcid.org/0000-0003-2196-2957 Ricardo Tadeu Santori ${ }^{\mathrm{C}}$ https://orcid.org/0000-0003-4694-8617 Veronica Eloi de Almeida ${ }^{\text {D }}$

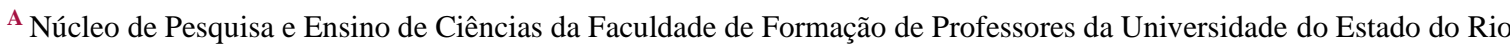
de Janeiro (Nupec; FFP; Uerj), São Gonçalo, RJ, Brasil

${ }^{\mathbf{B}}$ Escola Superior de Desenho Industrial da Universidade do Estado do Rio de Janeiro (Esdi; Uerj), Rio de Janeiro, RJ, Brasil

${ }^{\mathrm{C}}$ Programa de Pós-Graduação em Ensino de Ciências, Ambiente e Sociedade. Faculdade de Formação de Professores da Universidade do Rio de Janeiro (FFP; Uerj), São Gonçalo, RJ, Brasil

${ }^{\mathrm{D}}$ Centro Universitário Carioca (UniCarioca), Rio de Janeiro, RJ, Brasil

Recebido em: 12 mai. 2021 | Aceito em: 02 set. 2021

Correspondência: Pedro de Almeida Cunha (pedrocunhapedrao@gmail.com)
\end{abstract}

\begin{abstract}
Resumo
A partir de oficinas de videoaulas docentes em formação desenvolveram uma produção audiovisual utilizando ferramentas tecnológicas cotidianas acessíveis e de baixo custo como um meio de interação ensino e aprendizagem. A implementação de uma atividade, ministrada remotamente, através de ações práticas e enfoques metodológicos ativos, em duas disciplinas de uma licenciatura de ciências biológicas, em uma universidade pública do Estado do Rio de Janeiro, embasando-se em múltiplas referências, proporcionou uma vivência didática por meio de metodologias pautadas em tecnologias e atenta a cuidados a considerar ao utilizar tais ferramentas, sempre renovadas a partir do avanço tecnológico e demandas da sociedade.

Palavras-chave: formação de professores; tecnologias na educação; professor designer; ensino a distância.

Abstract

Based on video-class workshops, teachers in training developed audiovisual production using accessible and low-cost everyday technological tools as a means of teaching and learning interaction. The implementation of an activity, taught remotely, through practical actions and active methodological approaches, in two disciplines of a biological science degree, in a public university in the State of Rio de Janeiro, based on multiple references, provided a didactic experience through methodologies based on technologies and attentive to the care to consider when using such tools, always renewed based on technological advances and demands from society.
\end{abstract}

Keywords: teacher education; technologies in education; professor designer; distance learning. 


\section{Introdução}

No ensino de ciências e biologia, mais especificamente falando dos conteúdos da área de zoologia e bioevolução, o professor aborda conhecimentos sobre os animais, sua evolução, classificação, funcionamento, as relações entre si e com o ambiente. Na construção desse conhecimento, sobretudo em tempos de uso cada vez mais frequente de atividades não presenciais ou híbridas, é importante que o professor esteja atento às novas possibilidades de ensino e aprendizagem por meio das Tecnologias de Informação e Comunicação (TICs), utilizando suportes digitais cotidianos para interagir com os alunos e compartilhar conteúdos relativos às diferentes áreas do conhecimento. Tais tecnologias consistem basicamente nos meios usados para tratar a informação e auxiliar na comunicação, que vão desde computadores e smartphones até internet e aplicativos, explorando e favorecendo abordagens de diferentes estilos de aprendizagem (SILVA et al, 2019). Deste modo, a dinâmica da produção científica, seus métodos e os processos de socialização do conhecimento produzido, podem ser apresentados por meio de oportunidades de estudo e ações conectadas com a realidade visando o interesse do público-alvo.

Por mais que se incentive a utilização das inovações digitais no ensino e aprendizagem, e seu efetivo papel como estratégia didática, seu uso e logística na prática precisam avançar a fim de vencer as dificuldades, seja pela falta de estrutura, de metodologias específicas, ou de conhecimentos técnicos pelos atores envolvidos acerca dos recursos digitais (FILATRO, PICONEZ, 2008). Nesse sentido, novos tempos trazem a necessidade de novos métodos e estímulos ao processo educacional. Estudantes e professores podem aprender a construir seus conhecimentos estimulados pelo referencial tecnocultural atualizado constantemente pelas mídias e suas influências culturais. Tal estímulo pode trazer certa apropriação de produtos e conceitos no desenvolver do pensamento e do aprendizado (BARBERO,1997).

Conceitos e ideias vão se formando à medida que surgem novas tendências cotidianas, consequentemente alterando a percepção da realidade. Segundo Canclini (2010), é importante capacitar professores para a utilização de tecnologias nas práticas pedagógicas, por meio de ferramentas e recursos digitais de fácil acesso, permitindo formas didáticas para aplicativos utilizados pelo público-alvo em seu cotidiano, buscando inseri-las no processo de aprendizagem e de cidadania com ética e consciência crítica. Para Martins (2018), reconhecer a necessidade de um olhar múltiplo para a educação requer romper com o pensamento linear característico, lançando mão de uma visão heterogênea como ponto de partida para a construção do conhecimento. A assimilação de procedimentos do design thinking apresenta-se como uma importante estratégia para favorecer a perspectiva multirreferencial na abordagem de problemas que envolvam o ensino-aprendizagem.

Políticas públicas, quando constantemente atualizadas, disseminam o uso de ferramentas e acompanham a evolução das tecnologias. Observa-se que, na atual Base Nacional Curricular Comum - BNCC (BRASIL, 2017), das dez competências e habilidades a serem desenvolvidas pelos alunos, ao longo da educação básica, ao menos a metade possui fundamentos que possibilitam condições de aprendizado diretamente ligadas à inserção de 
tecnologias. Novas formas de fazer ganham vida por meio de exemplos práticos e interativos, inovando e mostrando potencialidades digitais no aprendizado, resultando em um aprender interativo com o uso de tecnologias integrado às atividades educativas (CAVALCANTI e FILATRO, 2018).

A necessidade de isolamento social demonstrou a um público abrangente, as diversas possibilidades que plataformas tecnológicas apresentam para entretenimento e educação, desenvolvendo habilidades e aproveitando a interatividade como um meio privilegiado de integração social. Educadores e educandos possuem, a partir de seus mobiles, aplicativos que permitem produzir e distribuir conteúdo em conjunto com processos educacionais. Dada a constante evolução tecnológica, faz-se necessário compreender em que medida essas tecnologias auxiliam na aprendizagem, entendendo essa ubiquidade na instrução em si, distinguindo-se de outros campos como a informação ou a comunicação (SANTAELLA, 2004).

Trabalhando-se no espaço-tempo em que o sujeito-professor está sendo formado, há maiores oportunidades para sensibilizá-lo para uma ação pedagógica mais significativa como prática educativa, problematizando e abordando situações complexas, com enfoque nas características do universo dos designers, integrando, assim, diversos elementos multirreferenciais em busca de soluções e proporcionando um diferencial inovador em relação a uma situação prévia (MARTINS, 2018).

Design Thinking é resumidamente designado, por Cavalcanti e Filatro (2018), como o conjunto de ideias e insights que, relacionando informações, análises, conhecimentos e entendendo métodos e processos, visa propor soluções. Além do caráter inovador adotado de forma multidisciplinar na atualidade, outras aplicações no âmbito da educação são observadas como estratégia de ensino-aprendizagem baseada em metodologias ativas a partir de soluções de problemas e projetos (CAVALCANTI e FILATRO, 2018).

O design é um campo de possibilidades imensas no mundo complexo em que vivemos. Por ser uma área voltada, historicamente, para o planejamento de interfaces e para a otimização de interstícios, ela tende a se ampliar à medida que o sistema se torna mais complexo e à medida que aumenta, por conseguinte, o número de instâncias de interrelação entre suas partes. $\mathrm{O}$ design tende ao infinito - ou seja, a dialogar em algum nível com quase todos os outros campos de conhecimento (CARDOSO,2013, p.128).

A produção de vídeo, por si só, já contém em si diversas tecnologias, como câmeras e aplicativos de edição, e conforme as necessidades para a finalização do projeto. Seu uso como ferramenta didática pode incentivar os futuros professores a conhecerem novos contextos utilizados em salas de aula, presenciais e virtuais (BASTOS et al. 2015).

Barcelos (2014) sustenta que, partindo de conteúdos audiovisuais, é possível gerar debates construindo conhecimento de forma lúdica, agindo como agregador e estimulador de trabalhos em grupo sobre o tema abordado. Assim, a aplicação pedagógica e proativa dos smartphones associada a uma linguagem compatível e persuasiva, pode estimular a construção de conhecimentos junto com novas técnicas e habilidades em prol de um objetivo comum.

Este estudo traz reflexões baseadas na realização de 02 oficinas de produção de videoaulas para licenciandos, estimulando o uso de tecnologias e aplicativos de fácil acesso, disponíveis, inclusive, em smartphones, a partir de experiências práticas com o uso de 
tecnologias no ensino e aprendizagem em disciplinas de zoologia e bioevolução. Baseadas no formato de Educação a distância (EaD), a atividade buscou apresentar formas e usos de recursos digitais e tecnologias na educação, a partir da capacitação básica para gravação, finalização e publicação de vídeos, dentro de um curso de licenciatura em ciências biológicas em uma universidade pública do Estado do Rio de Janeiro.

A primeira oficina ocorreu no segundo semestre letivo de 2019, onde as aulas na instituição ainda eram realizadas no modo presencial, embora a atividade tenha sido aplicada de forma remota. No segundo semestre de 2020, já durante o chamado período acadêmico emergencial, implantado por conta da Covid-19, a oficina foi novamente realizada, porém o ambiente remoto já se tornara a realidade no ensino e aprendizagem. Em ambos os casos, observando limites e possibilidades, buscou-se demonstrar uma vivência didática por meio de metodologias ativas, aqui embasadas entre outros autores, por Filatro (2008,2018), Martins (2016, 2017, 2018) e Santaella (2004), pautando-se em tecnologias renovadas a partir dos avanços na área e das demandas da sociedade.

As experiências das oficinas, em um período imediatamente anterior à chegada do Coronavírus ao Brasil, e durante o início do período letivo imediatamente seguinte, no regime de distanciamento social, apontam diversas questões pertinentes às tecnologias na educação e no ensino de ciências e biologia, refletem anseios e angústias que afligem hoje a sociedade moderna e novos paradigmas, bem como, as sempre renovadas demandas que envolvem as tecnologias, relações sociais e o comportamento humano.

\section{Métodos}

As oficinas de produção de videoaulas realizadas nesse estudo funcionaram como método de aprendizado prático intervindo diretamente no estudo, mapeando hipóteses a serem exploradas durante o processo e interagindo com o seu universo, partindo da própria atividade da oficina e de entrevistas com docentes de ciências biológicas do curso de licenciatura envolvido.

Foram realizadas 02 oficinas em turmas e períodos distintos na mesma licenciatura, uma antes da pandemia e outra no primeiro período letivo durante o distanciamento social. No primeiro caso, as aulas síncronas foram realizadas no modelo presencial pelo fato da dinâmica do curso de biologia se desenvolver neste ambiente. No segundo, devido às aulas estarem se realizando de forma remota, os encontros foram realizados por videoconferência.

A primeira oficina foi realizada na disciplina presencial de Zoologia V(Répteis, Aves e Mamíferos), no segundo semestre de 2019, onde os 15 alunos formaram grupos de 02 ou 03 componentes, totalizando 06 grupos. A segunda oficina foi ministrada no período letivo emergencial de 2020 e os 40 matriculados na disciplina de Bioevolução formaram, também, 06 grupos, porém de 05 a 06 componentes.

A pesquisa-intervenção, referencial teórico-metodológico no qual se baseou a pesquisa, se propõe a investigar as sociedades na sua diversidade qualitativa (AGUIAR e ROCHA, 2003). Dentre as estratégias utilizadas, a cartografia como método para as ciências humanas e sociais altera o modo de construção da pesquisa e a relação do pesquisador com seu campo, 
"valorizando para além dos discursos científicos, aquilo que se passa nas brechas dos episódios analisados entendendo-os como potencialmente formadores e criadores de realidade" (MARTINS, 2016 p. 24).

Foram entrevistados 06 professores, doutores e mestres, tendo como tópico guia da conversa a utilização de ferramentas digitais em suas atividades didáticas. Além do professor que encampou e se alinhou a pesquisa, abrindo suas disciplinas para que se ministrassem as oficinas, os outros nomes foram selecionados devido ao uso que fazem de tecnologias na educação, ou por sua ligação com o ensino de ciências e com a formação de professores. A entrevista pode fornecer informações básicas para as relações entre os dados envolvidos e a situação analisada, detalhando as motivações comportamentais em contextos sociais específicos (BAUER e GASKELL, 2002).

À medida que novas tendências cotidianas venham agregar valor à educação, sugere-se, através do auxílio de conceitos como a "behavioral meteorology" (meteorologia comportamental), que se possa coletar dados como faz a meteorologia tradicional, armazenando e criando hipóteses a serem exploradas ao longo do contínuo processo educacional. Interagindo com a sociedade, seus meios e tecnologias medem o "tempo comportamental" através de interações entre fatores situacionais e traços de personalidades estáveis (BAUER e GASKELL, 2002, p.156).

Delimitou-se o campo de estudo abrangendo os graduandos de ciências biológicas da instituição envolvida, associando-os ao estilo Visual, Auditivo ou Cinestético (VAC) de aprendizagem, no qual sentidos humanos são responsáveis pela apreensão do conhecimento. (VARK-LEARN, 2017).

\section{Entrevistas com professores}

Entrevistando individualmente docentes do curso de licenciatura em ciências biológicas da instituição, durante o segundo semestre de 2019, temas relativos às tecnologias na educação surgiram no discurso destes profissionais, refletindo a atualidade, onde ao mesmo tempo em que vivemos e aprendemos, consumimos e temos que nos adequar às sempre renovadas demandas que envolvem as ferramentas e suas relações com fatores inerentes às profissões e ao comportamento humano. Conviver e partilhar dados e ideias relativas ao projeto possibilitaram reflexões sobre a relevância da pesquisa na aprendizagem e na formação de professores.

O resultado da vivência apresentada, em conjunto com as experiências relatadas, depõe a favor do uso de estratégias ativas de aprendizagem e princípios característicos do design thinking, utilizando recursos lúdicos e ferramentas cotidianas como forma de atrair a atenção, a motivação e o conhecimento construído (MARTINS 2017).

\section{A oficina de produção de videoaulas}

Em busca de maior interação com o universo em questão, a pesquisa procurou criar soluções, através de enfoques metodológicos ativos, como sugerem Bauer e Gaskell (2002), a fim de conhecer detalhes do objeto de estudo e seus predicados, optou-se por proporcionar aos graduandos uma atividade de capacitação básica para produzir vídeos a partir de seus mobiles. 
Organizando-se em equipes, tiveram a tarefa de produzir e publicar na internet uma videoaula sobre um dos temas abordados nas disciplinas onde foram ministrados, utilizando alguma tecnologia como ferramenta didática no auxílio da proposta apresentada, em um vídeo de até 15 minutos de duração.

De uma forma geral, a atividade da produção de videoaulas envolve basicamente 04 etapas: (i) ideia e roteiro, onde formaram-se grupos, escolheram o tema e abordagem, fizeram o planejamento e preparação para a (ii) produção, fase em que devem escolher os equipamentos, os objetos de cena, funções da equipe e ações práticas visando a (iii) gravação, que requer alguns cuidados com a imagem, iluminação, captação de áudio, entre outras questões técnicas e por fim, (iv) a edição/finalização que requer softwares dedicados, que vão desde os programas mais sofisticados como Adobe Premiere, Final Cut até os mais simples e populares como Movie Maker ou o editor do Youtube, entre outros de fácil acesso e utilização através da internet.

Todos estes softwares fazem basicamente a mesma coisa: seleção e inclusão de gravações e imagens, montagem das cenas, transições e efeitos, legendas, sonorização, entre outros procedimentos que após a finalização resultam no produto audiovisual pronto para publicação (SOUZA FILHO et al, 2017).

Além do uso das câmeras presentes nos smartphones, estimulou-se, através de postagens no Ambiente Virtual de Aprendizagem (AVA), o uso de softwares de edição de imagens, inclusive no próprio celular, opções e programas dedicados à criação de conteúdo, aplicativos de comunicação, entre outras possibilidades de baixo custo ou gratuitos, visando implementar metodologias didáticas de inclusão digital sustentável e economicamente acessível, através de canais de amplo acesso e aceitação da população como um todo.

Após a confirmação de que todos os envolvidos na atividade utilizavam a rede social Facebook, um grupo fechado desta plataforma, configurado como sendo do tipo aprendizagem social, funcionou como AVA da oficina. Nestes grupos, dependendo da configuração, são adicionadas ferramentas específicas, funcionando como qualquer outro da referida rede social. Todavia, nos grupos configurados como aprendizagem social, os administradores podem interagir e verificar a ação dos participantes, lançar notas, tarefas, organizar publicações em unidades e ver estatísticas e detalhes sobre conclusão e feedback.

O material instrucional foi apresentado por meio de postagens no AVA, sendo ele o principal canal de comunicação e conteúdo da atividade, desde instruções básicas para a produção, edição e gravação de videoaulas com smartphones, até informações para utilização de tecnologias e softwares. A orientação individual foi feita via troca de mensagens, prioritariamente pelo mensageiro instantâneo Facebook Messenger, que fornece texto e comunicação por vídeo, embora outros meios ou aplicativos fossem eventualmente utilizados.

Conteúdos sobre tecnologias e seu uso em aulas de ciências e biologia foram apresentados através de publicações da própria rede social ou de fontes na internet, demonstrando ferramentas digitais, exemplos de videoaulas, tutoriais e sugestões a serem utilizadas nas propostas. Por questões logísticas, não foram avaliados conceitos através do canal, sendo a curadoria do material publicado realizada pelos docentes da atividade.

Em cada oficina aconteceram 02 encontros síncronos ou presenciais com as turmas objeto do estudo, com a duração média de 90 minutos cada, o primeiro visando à verificação do recebimento e entendimento da proposta, firmando-se um compromisso com os envolvidos. 
A partir de uma série de slides com exemplos de tecnologias, observando a aceitabilidade da proposta, possíveis empecilhos e grau de familiaridade com as TICs, formaram-se grupos com o objetivo de criar um roteiro/planejamento para uma videoaula sobre um dos temas abordados durante as respectivas disciplinas, propondo o uso de alguma tecnologia como ferramenta didática no auxílio da atividade apresentada no vídeo.

No segundo encontro, os grupos apresentaram, em uma roda de conversa, seus temas relativos ao conteúdo da disciplina e debateram, presencial ou virtualmente, como planejaram produzir a videoaula. Em 2019, a disciplina envolvida foi a de Zoologia V (Répteis, Aves e Mamíferos) e em 2020 foi a disciplina de Bioevolução.

A produção audiovisual foi adotada como uma das avaliações nas disciplinas, contando para a pontuação os seguintes critérios: conteúdo didático, produção e entrega do vídeo, participação, apresentação e fundamentação do uso de uma nova tecnologia como ferramenta didática no auxílio da atividade pedagógica desenvolvida. Os arquivos de vídeo foram entregues em formato de arquivo mp4 e postados, dentro do prazo definido, em endereço estipulado em uma nuvem de dados. Por ser uma atividade complementar dentro da licenciatura de ciências biológicas, não foram exigidas especificações técnicas de vídeo e publicação, bastando poder ser visualizado facilmente, estar em boa qualidade de exibição e de acordo com os quesitos propostos.

Questionários anônimos foram disponibilizados através do Google Forms, específicos para os participantes de cada uma das oficinas avaliarem a atividade. Na primeira experiência (2019) os participantes responderam a apenas 09 perguntas diretas sobre o evento. (aproveitamento das tecnologias apresentadas, aprovação da metodologia e do AVA, dificuldades e sugestões para a atividade.) Após a segunda oficina (2020), a partir da necessidade da assimilação do ensino remoto de uma forma mais ampla pela sociedade, formulou-se um questionário mais detalhado, com 29 perguntas sobre os aspectos das vivências digitais do universo envolvido, buscando-se informações além do uso das TICs propriamente na atividade.

\section{Resultados e discussão}

Considerando que videoaulas contribuem para o ensino e a aprendizagem, e a totalidade dos licenciandos pesquisados possuir smartphones, os sujeitos da pesquisa aprenderam a fazer uso de dispositivos móveis como ferramenta ativa na produção de conteúdo digital. As oficinas possibilitaram a utilização de recursos tecnológicos do cotidiano como um meio de aprendizagem, e interação. Respeitados os critérios da entrega do arquivo, e não sendo a produção audiovisual o foco principal de um curso de biologia, os vídeos surpreenderam pela criatividade e qualidade, contribuindo significativamente para o conhecimento e o desenvolvimento avaliativo do aluno nas disciplinas.

Na primeira oficina, realizada na disciplina de Zoologia V, durante o segundo semestre de 2019, os grupos postaram as videoaulas: 1. Cetáceos e relações filogenéticas; 2 . Quem veio primeiro, o ovo ou a galinha? 3. Mamíferos, tipos de patas e hábitos de vida; 4. O Movimento das Serpentes; 5. Diferenças morfológicas e ecológicas entre os bicos das aves; 6 . Curiosidades populares sobre o tema evolução. 
Os questionários, de 09 perguntas, disponibilizados durante o segundo semestre de 2019, buscaram verificar a opinião dos 15 participantes da primeira oficina sobre a atividade. Doze alunos responderam, constatando-se que: $75 \%$ por cento aproveitaram em seu dia a dia alguma das tecnologias apresentadas; $80 \%$ pretendiam utilizar ou se aprofundar em algum dos conteúdos abordados na oficina, com destaque para os voltados para a produção e edição de vídeos; $90 \%$ consideraram que videoaulas contribuem no ensino e aprendizagem de conteúdo; $66 \%$ aprovaram o modelo de educação à distância através do grupo da videoaula no Facebook como ambiente virtual de aprendizagem (AVA); $25 \%$ acharam que este pode ser aprimorado.

Observando em questões relativas ao trabalho em casa e a necessidade de ensino remoto a possibilidade de adaptar atividades também com a formação de subgrupos para execução de projetos, tarefas e resolução de problemas, durante o distanciamento social, no ano de 2020, trabalhando de forma exclusivamente remota, a segunda oficina, realizada na disciplina de Bioevolução da mesma licenciatura de ciências biológicas, desenvolveu videoaulas com os seguintes temas: 1. Darwinismo Social; 2. Evidências do processo evolutivo; 3. Darwinismo vs. Lamarckismo; 4. Deriva Genética; 5. Evidências evolutivas; 6. Mutação.

A experiência da primeira oficina, realizada em 2019, e as consequências da assimilação do ensino remoto de uma forma mais ampla em 2020, levaram a formulação de um questionário mais detalhado, com 29 perguntas relativas a esta segunda edição da atividade e aspectos das vivências digitais dos envolvidos. Dos 29 participantes que responderam ao questionário, afirmando, preferencialmente acessar a internet e as redes sociais a partir de seus smartphones, se conectando através de redes $w i-f i$, apenas três não pretendiam atuar profissionalmente como professor. Aproximadamente $80 \%$ consideraram ter conhecimentos básicos ou intermediários sobre o funcionamento de seus aparelhos celulares e em relação ao uso mais abrangente de tecnologias; $10 \%$ se consideraram usuários avançados; $48 \%$ intermediários e $41 \%$ básicos. Os participantes da oficina disseram preferir a utilização da internet para: observar $79 \%$, ler $51 \%$, ouvir 44\% e interagir 37\%. Quanto às redes sociais, as principais citadas foram pela ordem: Instagram, Facebook, YouTube e Twitter. Além disso, consideraram aprender melhor: fazendo $37 \%$, ouvindo $27 \%$, observando $24 \%$ e lendo $10 \%$. Cerca de $80 \%$ disseram que pretendiam utilizar ou se aprofundar em algum dos conteúdos abordados na oficina, com destaque para os voltados para a produção e finalização de vídeos. Todos os respondentes consideraram o potencial das videoaulas para a aprendizagem e assimilação de conteúdo e 15 afirmaram ter aproveitado em seus cotidianos, ao menos em parte, alguma das tecnologias apresentadas na oficina.

Em relação às videoaulas propriamente, em ambas as oportunidades, o maior complicador foi a edição e finalização dos vídeos, fator influenciado por inúmeras variantes, muitas vezes fugindo ao controle imediato, como: problemas de falta de conexão, tempo para atividade dentro da disciplina, pré-disposição para assimilação de conhecimentos técnicos e operacionais básicos para a produção do vídeo e a própria diversidade de opções de aplicativos e equipamentos disponíveis. Porém, os problemas incentivaram a busca de soluções para esses desafios, sendo demonstrado interesse nos conteúdos apresentados.

Nas duas ocasiões, verificou-se a necessidade de maior atenção aos aspectos da finalização audiovisual, o que no caso não foi possível por ser a oficina uma atividade 
complementar das disciplinas, que possuíam um cronograma e conteúdo preestabelecido pelos docentes responsáveis, que deveria ser cumprido.

O grupo da oficina do Facebook, configurado como AVA, foi avaliado positivamente pelos alunos participantes, porém afirmando que poderia melhorar. Já habituados a acessar a dita rede social, lá interagiram com a turma e acessaram publicações com conteúdo sobre tecnologias e produção de vídeos, enquanto os administradores puderam monitorar a ação dos participantes no ambiente, lançar conteúdos, tarefas, organizar e ver estatísticas, detalhes e feedback.

$\mathrm{O}$ isolamento social acentuou a necessidade de que os professores tivessem algum conhecimento básico com o ferramental tecnológico utilizado por seu público-alvo, para que pudessem disponibilizar conteúdos e videoaulas na internet, sendo uma habilidade cada vez mais exigida pelas diversas instituições de ensino, desde a educação básica até a pós-graduação.

Dentre os temas mapeados, cruzando as informações e observações, tanto na dinâmica da oficina quanto na fala dos docentes, descritas abaixo, há de se ter atenção e avaliar o quanto podemos estar nos tornando reféns das tecnologias, observando a aparente dificuldade de alguns em distinguir as informações que recebem, sendo guiados pelo grau de inovação da mídia e não pela credibilidade e qualidade do que está sendo citado. Como afirmou em seu depoimento a Professora Doutora Regina Mendes:

Há quase uma incongruência das novas tecnologias com o modo de agir que não muda, depende muito da motivação do ser humano, que muitas vezes só muda o foco, a plataforma passou do papel para tela, porém o processamento cognitivo é o mesmo (MENDES apud CUNHA, 2019, p. 68).

A interação e o fluxo contínuo de ideias podem, e devem contribuir para o encontro de soluções possíveis para as diferentes variáveis a serem encontradas em cada situação. Metodologias ativas como as elencadas permitem ser utilizadas com grande proveito devido a sua diversidade e capacidade de adaptação, pois se alimenta exatamente destas interações com os sujeitos, o ambiente e os dados da pesquisa.

Embora haja bastante motivação com o uso de ferramentas tecnológicas nas atividades propostas, os docentes entrevistados alertam, é preciso tomar cuidados com a utilização das tecnologias, principalmente com o conteúdo a ser trabalhado por meio delas. "A verificação da informação se mostra cada vez mais essencial diante dos atuais argumentos pretensamente científicos respaldados por uma boa qualidade de edição de fatos, textos, contextos e imagens", alerta o Professor Doutor Dorvillé (apud CUNHA, 2019, p.63).

\footnotetext{
Diferem nas ditas novas tecnologias, a forma como se lida com o conhecimento e como usar essas ferramentas de maneira que venham realmente a somar, esbarrando em uma série dificuldades como, entre outras, falta de conectividade, rede instável, disponibilidade de recursos, qualidade do material, além do conhecimento para o professor saber como, de que maneira e onde utilizar esses dispositivos (Prof. Dr. GUERRA apud CUNHA 2019, p.64 - 65).
}

O Ensino remoto emergencial acelerou e intensificou uma angústia docente de não estar conseguindo dar conta das TICs na educação, desconfiados sobre as reais possibilidades 
oferecidas em uma realidade que parece irreversível. Iniciativas como a oficina são importantes para romper essas barreiras, pois trabalham com ferramentas do cotidiano.

Pretendendo criar empatia entre a disciplina, o professor e o estudante, abrangendo aspectos interdisciplinares e sociais para além da escola, a atividade da oficina aproveitou-se da alta aceitação e usabilidade dos smartphones, privilegiando o formato do vídeo, um dos meios mais democráticos e acessíveis (BARCELOS, 2014), e presente nos mobiles de todas as camadas sociais, sem necessariamente precisar de conexão constante à internet.

No início deste século XXI, a UNESCO concordava que "uma nova educação torna-se imprescindível para que se avance em direção à universalização da cidadania. Para isso, ideias devem ser exaustivamente debatidas por todos os responsáveis pela formulação e execução das políticas educacionais" (WERTHEIN; CUNHA (UNESCO), 2005, p.09). O campo do design thinking pode inserir e construir possibilidades na educação, aqui especificamente na formação de professores a partir de projetos e desafios apresentados.

Observando o aproveitamento de TICs apresentadas, é perfeitamente possível afirmar que possam desempenhar um papel mais efetivo como ferramental didático, incentivando assim a utilização e conhecimento dessas ferramentas para um uso produtivo.

\section{Conclusão}

Com o significativo aumento e diversificação do uso das Tecnologias de Informação e Comunicação com fins educacionais, o estudo espera contribuir para a formação de futuros professores. Tais recursos devem ser utilizados para auxiliar na educação sempre entendendo o estudante como sujeito, seu papel social e lugar que ocupa, e não devem ser definidoras profissionais na formação do professor, que deve ser focada em uma sólida base intelectual, sociológica e acadêmica.

Outras disciplinas, formatos e modelos de aprendizagem podem ser criados a partir desta experiência, em cursos de diversas áreas, além de parcerias com instituições, aplicativos e desenvolvedores de soluções para educação. Colaborando para a divulgação do conhecimento, os dados ora levantados e debatidos contribuem para uma reflexão em busca de caminhos para o uso mais consciente e produtivo das tecnologias na educação.

Com variadas ferramentas, constituídas por diferentes tecnologias, a oficina de produção de videoaulas aparentemente cumpre seu principal objetivo, demonstrando como é possível proporcionar uma vivência didática por meio de metodologias ativas e baseadas em projetos pautados em TICs, com uso consciente, ético e funcional dessas possibilidades, renovadas a partir do avanço tecnológico e das demandas da sociedade.

As experiências relatadas no artigo, ocorridas durante o segundo semestre letivo de 2019, anterior à Covid-19, e no primeiro semestre letivo de 2020 (período acadêmico emergencial). Ao observar os dados e o perfil destes futuros professores de ciências e biologia, reflete-se sobre o uso de tecnologias sustentáveis e economicamente acessíveis através de canais digitais de fácil utilização e aceitação, levando em conta estímulos e estilos de aprendizagem. 
O uso da cultura digital e a dinâmica da produção científica, seus métodos e processos de socialização do conhecimento, produzem e apresentam a estudantes e professores oportunidades de estudo e ações conectadas com inovações da realidade cotidiana. Como proposta, as informações levantadas neste estudo indicam a necessidade da oferta de disciplinas dedicadas às tecnologias na educação como parte integrante do currículo das licenciaturas, por conta do papel que ocupam no processo educacional ${ }^{\mathrm{i}}$.

\section{Referências}

BARCELOS, Alessandra da C. et al. As aves através da janela: produção de vídeos sobre ornitologia para uso educacional. Boletim Informativo Sociedade Brasileira de Zoologia. Curitiba, Ano XXXVI - Número 111 pág. 10 e 11, 2014. Disponível em:

<http://sbzoologia.org.br/uploads/1461609876-111.pdf>. Acesso em: 28 abr. 2021.

BASTOS, W.; REZENDE Filho, L. A. C.; PASTOR Junior, A. A Produção de Vídeo Educativo por Licenciandos: um estudo sobre recepção fílmica e modos de leitura. Ensaio em Ciências (Online), Belo Horizonte - MG, v. 17, p. 39-58 2015. Disponível em:

<http://www.scielo.br/scielo.php?script=sci_arttext\&pid=S198321172015000100039\&lng=pt\&nrm=iso\&tlng=en>. Acesso em: 10 set. 2021.

BAUER, Martin W; GASKELL George (editores). Pesquisa qualitativa com texto: imagem e som: um manual prático - tradução de Pedrinho A. Guareschi (Título original: Qualitative Researching with Text, Image and Sound: a Practical Handbook.) Petrópolis-RJ: Vozes, 2002.

BRASIL. Base Nacional Comum Curricular (BNCC). Brasília, MEC/CONSED/UNDIME, 2017. Disponível em: 〈http://basenacionalcomum.mec.gov.br>. Acesso em: 1 abr. 2021.

CANCLINI, Néstor G. Consumidores e cidadãos. Rio de Janeiro: Ed. UFRJ — 2010.

CARDOSO, Rafael. Design para um mundo complexo. São Paulo: Cosac Naify, 2013.

CAVALCANTI, Carolina Costa; FILATRO, Andrea Cristina. Metodologias capacidade de obter uma compreensão intuitiva precisa e profunda de uma pessoa ou coisa. São Paulo: Saraiva UNI, 2018.

CUNHA, Pedro de Almeida. Oficina de produção de videoaulas na Formação de professores de biologia: Linguagem audiovisual e uso didático de recursos digitais/ Tese Mestrado, Rio de Janeiro: Mestrado Profissional em Novas Tecnologias Digitais na Educação do Centro Universitário Carioca, 2019.

FILATRO, Andrea; PICONEZ, Stela. Contribuições do design instrucional e do learning design para a organização do trabalho pedagógico. In: J. Sánchez (Ed.). Nuevas Ideas en Informática Educativa, Santiago de Chile, Volumen 4, pp. 81-88, 2008. Disponível em: <http://www.tise.cl/volumen4/TISE2008/Documento11.pdf〉. Acesso em: 3 maio 2021. 
FLEMING, N. D. Teaching and learning styles: VARK strategies. Christchurch, New Zealand, 2001. VARK, A Guide to Learning Styles, Springfield, MO.,2017. Disponível em: <http://www.vark-learn.com>. Acesso em: 21 de abr. 2021.

MARTINS, Bianca Maria Rêgo. O Professor-Designer de experiências de aprendizagem: tecendo uma epistemologia para a inserção do design na Escola/ Tese doutorado. Rio de Janeiro: Pontifícia Universidade Católica do Rio de Janeiro, Departamento de Artes e Design, 2016.

MARTINS, Bianca Maria Rêgo; NOLASCO-SILVA, Leonardo. O professor-designer de experiências de aprendizagem: autoria docente e uso de recursos lúdicos na formação de professores. Revista Carioca de Ciência, Tecnologia e Educação (online). Rio de Janeiro, v. 2 | n. 1, 2017. Disponível em:

$<$ https://recite.unicarioca.edu.br/rccte/index.php/rccte/article/view/17/65>. Acesso em: 18 abr. 2021.

MARTINS, Bianca Maria Rêgo; COUTO, Rita. Discursos orientadores do uso do design em práticas educativas. Revista Carioca de Ciência, Tecnologia e Educação (online), Rio de Janeiro, v. 3 |n. 1. 2018. Disponível em:

<https://recite.unicarioca.edu.br/rccte/index.php/rccte/article/view/36>. Acesso em: 18 abr. 2021.

SANTAELLA, Lucia. Navegar no Ciberespaço. São Paulo: Paulus, 2004.

SILVA, Fabiana Adão et al. O modelo ead e estilos de aprendizagem: um estudo de caso no Colégio Pedro II. EAD em Foco, Rio de Janeiro, v. 9, n. 1, set. 2019. Disponível em: $<$ http://eademfoco.cecierj.edu.br/index.php/Revista/article/view/770/373doi:https://doi.org/10 .18264/eadf.v9i1.770>. Acesso em: 21 abr. 2021.

SOUZA FILHO et al. Uso de recursos tecnológicos no ensino de ciências: produção de videoaulas didáticos - experimentais pelos futuros professores. Nuances: Estudos sobre Educação, UNESP, São Paulo v.28, n.3, 2017. Disponível em <https://revista.fct.unesp.br/index.php/Nuances/article/view/41496>. Acesso em: 21 abr. 2021.

WERTHEIN, Jorge; CUNHA, Célio. Fundamentos da nova educação. Brasília: Cadernos UNESCO. Série: Educação, v. 5. 2005. Disponível em: <http://unesdoc.unesco.org/images/0012/001297/129766por.pdf>. Acesso em: 30 abr. 2020.

\footnotetext{
' Agradecimentos: Os autores gostariam de agradecer a todos que apoiaram e tornaram possível a realização desta pesquisa. À Faculdade de Formação de Professores da UERJ, seus estudantes, professores e colaboradores, que a partir do Núcleo de Pesquisa e Ensino de Ciências - NUPEC - permitiu e incentivou as atividades realizadas neste estudo. Ao suporte acadêmico oferecido pelo Programa de Mestrado Profissional em Novas Tecnologias Digitais na Educação do Centro Universitário UniCarioca. À Pró-Reitoria de Pós-Graduação e Pesquisa da UERJ (PR2), pela bolsa PROATEC concedida a P. A. Cunha. À FAPERJ, pelos auxílios à pesquisa concedidos à R. T. Santori.
} 